\title{
Henri Scepi, Poésie vacante: Nerval, Mallarmé, Laforgue
}

\section{Ida Merello}

\section{(2) OpenEdition}

1 Journals

\section{Edizione digitale}

URL: http://journals.openedition.org/studifrancesi/8331

DOI: 10.4000/studifrancesi.8331

ISSN: 2421-5856

\section{Editore}

Rosenberg \& Sellier

\section{Edizione cartacea}

Data di pubblicazione: 1 mai 2009

Paginazione: 200

ISSN: 0039-2944

\section{Notizia bibliografica digitale}

Ida Merello, «Henri Scepi, Poésie vacante: Nerval, Mallarmé, Laforgue», Studi Francesi [Online], 157 (LIII I

I) | 2009, online dal 30 novembre 2015, consultato il 12 janvier 2021. URL: http://

journals.openedition.org/studifrancesi/8331 ; DOI: https://doi.org/10.4000/studifrancesi.8331

Questo documento è stato generato automaticamente il 12 janvier 2021.

\section{(c) (i) (9)}

Studi Francesi è distribuita con Licenza Creative Commons Attribuzione - Non commerciale - Non opere derivate 4.0 Internazionale. 


\title{
Henri Scepi, Poésie vacante: Nerval, Mallarmé, Laforgue
}

\author{
Ida Merello
}

\section{NOTIZIA}

HENRI SCEPI, Poésie vacante: Nerval, Mallarmé, Laforgue, Lyon, Ens éditions, 2008, pp. 244.

1 L'A. ripercorre le profonde modifiche sulle forme letterarie operate dal Romanticismo e portate avanti nel corso del secolo - emancipazione dai generi, interiorizzazione della parola poetica - rintracciando nei tre autori in oggetto un analogo atteggiamento di chiusura al mondo e rifiuto di confronto con la storia, che si manifesta in Nerval come ripiegamento nel mito, in Mallarmé come splendido isolamento, e in Laforgue come rifiuto radicale. I tre poeti denunciano dunque per quanto in maniera diversa l'impossibilità di farsi carico della realtà, e alla poesia affidano il compito di superare tale vacanza nell'assolutezza della forma e della parola. L'A. vede alla base della poesia di Nerval la ricerca di una "propriété fixante", contro il rischio di dispersione: proprietà che si manifesta a livello di macrostruttura, nel principio di insistenza e ripetizione, e a livello di microanalisi del testo, sotto forma di circuiti di motivi identici. Per seguire la parabola di Mallarmé l'A. riprende invece alcuni testi chiave, come Les fenêtres e Hérodiade, mettendo in evidenza il passaggio dall'ossessione dell'azzurro al ripiegamento verso il nulla, l'assenza e la morte. Il testo poetico diventa infatti lo spettacolo dell'astrazione del linguaggio e dell'annullamento degli oggetti. Anche in Laforgue il linguaggio è al centro dell'attenzione, per essere decostruito (désécrit secondo l'espressione di Albalat ripresa dall'A.) rispetto alla retorica tradizionale. Se l'appropriazione soggettiva della lingua è in realtà un aspetto comune alla koiné decadente, a tal punto che la critica ha messo spesso in rapporto Laforgue con l'impressionismo dei Goncourt, l'A. rivendica l'originalità assoluta del poeta, per cui i Goncourt hanno rappresentato solo un modello di autonomia. La libertà stilistica coincide in lui con la ricerca di nuove sonorità e nuovi ritmi, rinforzata dal costante 
humour che ha un effetto di corrosione della tradizione poetica, portando a una messa a nudo del linguaggio e a un'apertura sul nuovo. 